\title{
On two speed optimization problems for ships that sail in and out of emission control
} areas

\section{Fagerholt, Kjetil; Psaraftis, Harilaos N.}

\section{Published in:}

Transportation Research. Part D: Transport \& Environment

Link to article, DOI:

10.1016/j.trd.2015.06.005

Publication date:

2015

Document Version

Peer reviewed version

Link back to DTU Orbit

\section{Citation (APA):}

Fagerholt, K., \& Psaraftis, H. N. (2015). On two speed optimization problems for ships that sail in and out of emission control areas. Transportation Research. Part D: Transport \& Environment, 39, 56-64.

https://doi.org/10.1016/j.trd.2015.06.005

\section{General rights}

Copyright and moral rights for the publications made accessible in the public portal are retained by the authors and/or other copyright owners and it is a condition of accessing publications that users recognise and abide by the legal requirements associated with these rights.

- Users may download and print one copy of any publication from the public portal for the purpose of private study or research.

- You may not further distribute the material or use it for any profit-making activity or commercial gain

- You may freely distribute the URL identifying the publication in the public portal 


\title{
On two speed optimization problems for ships that sail in and out of emission control areas
}

\author{
Kjetil Fagerholt ${ }^{1,2}$ and Harilaos N Psaraftis ${ }^{3^{*}}$ \\ ${ }^{1}$ Department of Industrial Economics and Technology Management, Norwegian University of \\ Science and Technology, Trondheim, Norway \\ ${ }^{2}$ Norwegian Marine Technology Research Institute (MARINTEK), Trondheim, Norway \\ ${ }^{3}$ Department of Transport, Technical University of Denmark, Lyngby, Denmark
}

Date: 11th of May, 2015

\begin{abstract}
This paper deals with two speed optimization problems for ships that sail in and out of Emission Control Areas (ECAs) with strict limits on sulphur emissions. For ships crossing in and out of ECAs, such as deep-sea vessels, one of the common options for complying with these limits is to burn heavy fuel oil (HFO) outside the ECA and switch to low-sulphur fuel such as marine gas oil (MGO) inside the ECA. As the prices of these two fuels are generally very different, so may be the speeds that the ship will sail at outside and inside the ECA. The first optimization problem examined by the paper considers an extension of the model of Ronen (1982) in which ship speeds both inside and outside the ECA are optimized. The second problem is called the ECA refraction problem, due to its conceptual similarity with the refraction problem when light travels across two different media, and also involves optimizing the point at which the ship crosses the ECA boundary. In both cases the objective of the problem is to maximize daily profit. In addition to mathematical formulations, examples and sensitivity analyses are presented for both problems.
\end{abstract}

Keywords: Maritime transportation, speed optimization, emission control areas

*Corresponding Author: Phone: +45 40484796, Email: hnpsar@transport.dtu.dk 


\section{INTRODUCTION}

Ocean-going vessels carry more than 90 per cent of global trade (IMO, 2014), and shipping is considered an environment-friendly mode of transport. However, there are still significant emissions associated with shipping operations. Emissions from the shipping industry are closely correlated to its consumption of fuel, which has been estimated to be between 279 and 400 million tons (Cullinane and Bergqvist, 2014). The so-called Third IMO GHG study 2014 (Smith et al, 2014) provided updated estimates of carbon dioxide $\left(\mathrm{CO}_{2}\right)$ emissions from international shipping from 2007 to 2012. The 2012 figure was 796 million tonnes, down from 885 million in 2007, or $2.2 \%$ of global $\mathrm{CO}_{2}$ emissions. $\mathrm{CO}_{2}$ from all shipping was estimated at 940 million tonnes, down from 1,100 tonnes in 2007 . The reduction was mainly attributed to slow steaming.

As early as in 1997 in Kyoto, the United Nations Framework Conference on Climate Change (UNFCCC) designated the International Maritime Organization (IMO), the United Nations specialized agency with responsibility for the safety and security of shipping and the prevention of marine pollution by ships, as the body responsible for regulating maritime air emissions. In 2008, the Marine Environment Protection Committee (MEPC) of the IMO adopted amendments to the MARPOL Annex VI regulations that deal with $\mathrm{SO}_{x}$ and $\mathrm{NO}_{x}$ emissions. These amendments set the global limit on the sulphur content of a ship's fuel to $3.50 \%$ (from 2012) followed by a reduction to $0.50 \%$ from 2020 (though subject to a review to be completed by 2018 which may conclude to prolong this stricter requirement to 2025).

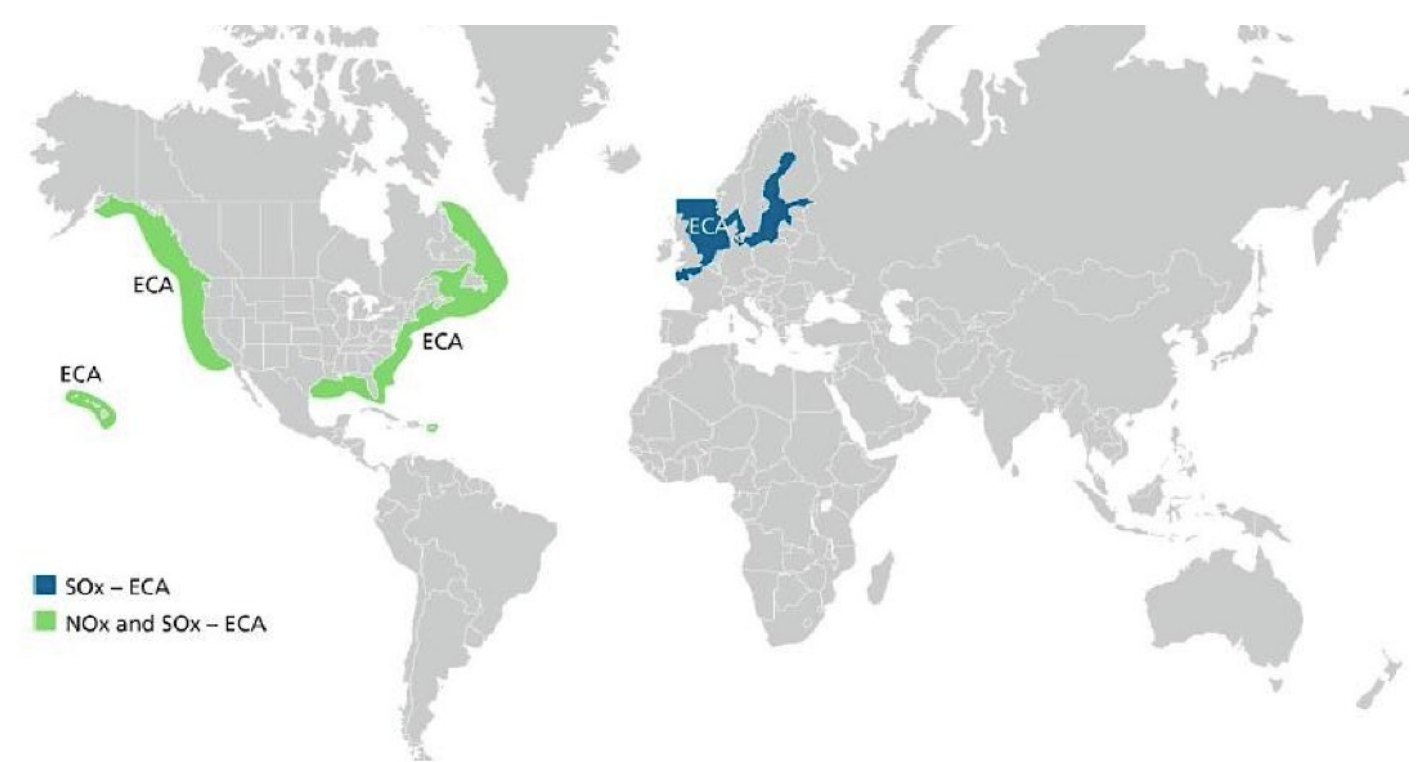

Figure 1: Map over current Emission Control Areas (Fagerholt et al., 2015)

Four Emission Control Areas (ECAs) have also been defined by MARPOL, as shown in Figure 1. These are the Baltic Sea, the North Sea and English Channel, and the North 
American and the US Caribbean coasts. The North American ECA applies to all ships sailing within 200 nautical miles of the North American coastline, including Canada, while for the other ones they are as illustrated in Figure 1. Within these ECAs there is even more stringent control of the sulphur emissions with a limit of $0.1 \%$ sulphur content in the ship's fuel from January 1, 2015. The North American and US Caribbean ECAs also regulate $\mathrm{NO}_{\mathrm{x}}$ emissions. In addition, the EU has adopted legislation transposing the IMO regulations into EU law, the latest version of which is Directive 2012/33/EU (also known as the sulphur directive). The sulphur directive is more stringent than MARPOL Annex $\mathrm{VI}$, as irrespective of the outcome of the proposed IMO review in 2018 , a reduction to a cap of $0.50 \%$ sulphur content will be unilaterally implemented in the EU on 1 January 2020 and also all passenger ships in the EU's non-ECA waters will have a maximum $1.5 \%$ sulphur content until that time.

There are mainly three ways shipping companies can achieve compliance with the ECA sulphur regulations, i.e. fuel switching, installing a scrubber and using liquefied natural gas (LNG) as fuel. For ships that operate both within and outside ECAs, such as deep-sea vessels, fuel switching is a straightforward compliance alternative. This means that the ships burns marine gas oil (MGO) within ECAs, while the more commonly used and cheaper fuel type, heavy fuel oil (HFO), is used outside. The ability to switch fuels is a necessity for deep-sea vessels that cross in and out of ECAs, so these ships need to keep two sets of segregated fuel tanks, one for HFO and another for MGO. Modifications should also be made in the fuel pump system and would also involve installing a fuel switch and a cooler, as HFO is preheated whereas MGO should be injected cold. The corresponding investment costs are ship dependent but in any event are about an order of magnitude lower as compared to the other two compliance options (see below).

The second option is to install a scrubber, which is a filtering/cleaning system to remove the sulphur from the exhaust. This permits the ship to use HFO in ECAs. The scrubber solutions are usually not considered cost effective for deep-sea vessels as the portion of time they spend in ECAs is low.

The third alternative involves using liquefied natural gas (LNG) as fuel. This virtually eliminates emissions of sulphur and potentially many other substances such as nitrogen oxides. This involves high investments for retrofitting the ship so that it can store and burn LNG, and also making sure there are adequate shoreside LNG supply facilities at the ports in which the ship will refuel.

Compliance with ECA regulations has received significant attention lately, both from shipping companies and from the research community. A recent special issue in 
Transportation Research Part D (Cullinane and Bergqvist, 2014) included several papers examining the ECA issue from various angles. These included Jiang et al. (2014) who performed an economic analysis to compare scrubbers and fuel switching, and Panagakos et al. (2014) who examined the possible designation of the Mediterranean as a Sulphur ECA. Brynolf et al. (2013), and Balland et al. (2012; 2013) also analyzed $\mathrm{SO}_{x}$ compliance in combination with $\mathrm{NO}_{x}$ abatement.

Fagerholt et al. (2015) developed an optimization model to be applied by ship operators for determining optimal routing and sailing speeds for a ship along a given sequence of ports, where some of the sailing is within ECAs. The objective was to minimize fuel costs. The paper considered fuel switch as a compliance means. A computational study was performed on a number of realistic shipping routes in order to evaluate possible impacts on fuel consumption and costs from the speed and routing decisions resulting from the ECA regulations. In contrast to what we do in this paper, Fagerholt et al. (2015) minimized costs and assumed there were time windows at the ports along the route.

In this paper we consider two new speed optimization problems that arise for ships that use fuel switch and sail in and out of ECAs, such as for instance deep-sea vessels. The first problem, studied in Section 2, is similar as the one introduced by Ronen (1982) in his pioneering paper on speed optimization, though extended to the situation with ECAs. The second problem we consider, presented in Section 3, is the so-called ECA-refraction problem. This problem also considers determining the sailing path between a port within the ECA and one outside the ECA, including the crossover point through the ECA boundary. In both cases the objective of the problem is to maximize daily profit. It should be emphasized that when maximizing daily profit, there is a tradeoff between the revenue and the fuel costs. A higher speed increases the revenue per time unit as the ship will be able to perform more voyages, but this also increases fuel consumption and fuel cost. For each of these two speed optimization problems with ECAs we propose a mathematical formulation and provide some test examples including sensitivity analysis.

\section{EXTENSION OF RONEN'S APPROACH TO ECAS}

Ronen (1982) considered determining the optimal speed for three different types of voyages, where his Model 1 for an income generating leg probably has the most practical applicability. Therefore, we consider this type of voyage and extend Ronen's model to the case where the sailing leg is partially within the ECA and partially outside. This means there is a given distance within the ECA where the ship must use the more expensive fuel (e.g. MGO) and a given distance outside where the ship can consume normal fuel (HFO). Because of the differences of fuel prices and 
the convex non-decreasing fuel consumption as a function of speed, it will generally be optimal to sail with different speeds within and outside the ECA.

The problem therefore consists of determining the optimal speeds on the sailing leg within and outside the ECA.

\subsection{Mathematical formulation}

The following model assumes a cubic fuel consumption function as in Ronen (1982), i.e. the fuel consumption per time unit increases to the power of three with speed. This is a reasonable approximation for most cargo ships even though there might ship types where other approximations would be better, see the discussion in Psaraftis and Kontovas (2013). It should be noted that the following model can be modified also to other fuel consumption functions.

We define the following notation.

Input parameters:

$R \quad$ Revenue for the given sailing leg

$C_{E} \quad$ Cost per tonne of fuel inside ECA (i.e. cost of MGO)

$C_{N} \quad$ Cost per tonne of fuel outside ECA (i.e. cost of HFO)

$D_{E} \quad$ Distance within ECA for the sailing leg analyzed

$D_{N} \quad$ Distance outside ECA for the sailing leg analyzed

$\bar{V} \quad$ Maximum sailing speed

$\underline{V} \quad$ Minimum sailing speed

$F \quad$ Conversion factor between speed and fuel consumption. $F$ is such that the daily fuel consumption at speed $v$ is equal to $F v^{3}$.

Variables:

$v_{E} \quad$ Sailing speed within ECA

$v_{N} \quad$ Sailing speed outside ECA

$t_{E} \quad$ Duration spent inside ECA (auxiliary variable)

$t_{N} \quad$ Duration spent outside ECA (auxiliary variable)

The cost of fuel consumed inside the ECA is ${ }^{1}$

$$
F C_{E} v_{E}^{3} t_{E}=F C_{E} D_{E} v_{E}^{2}
$$

while the cost for the fuel used outside is

$$
F C_{N} D_{N} v_{N}^{2}
$$

\footnotetext{
${ }^{1}$ To avoid dividing by 24 , we assume that speeds are expressed in nautical miles per day.
} 
This gives the following total fuel cost per sailing leg:

$$
F C_{E} D_{E} v_{E}^{2}+F C_{N} D_{N} v_{N}^{2}
$$

The total profit (or actually gross margin to be precise) per sailing leg is given as the revenue minus the total fuel cost, and is given as follows:

$$
R-F C_{E} D_{E} v_{E}^{2}-F C_{N} D_{N} v_{N}^{2}
$$

The objective is to maximize the profit per time unit (i.e. daily profit), which is the total profit divided by the total number of sailing days (for simplicity we leave out the port days as this can be considered fixed). This gives the following expression for the daily profit:

$$
\frac{\left(R-F C_{E} D_{E} v_{E}^{2}-F C_{N} D_{N} v_{N}^{2}\right)}{t_{E}+t_{N}}=\frac{\left(R-F C_{E} D_{E} v_{E}^{2}-F C_{N} D_{N} v_{N}^{2}\right)}{\frac{D_{E}}{v_{E}}+\frac{D_{N}}{v_{N}}}
$$

The optimization problem then becomes:

$$
\max \quad z=\frac{\left(R-F C_{E} D_{E} v_{E}^{2}-F C_{N} D_{N} v_{N}^{2}\right)}{\frac{D_{E}}{v_{E}}+\frac{D_{N}}{v_{N}}}
$$

subject to

$$
\underline{V} \leq v_{E}, v_{N} \leq \bar{V}
$$

This can be solved in a similar way as by Ronen (1982), by setting the partial derivatives of $z$ with respect to $v_{E}$ and $v_{N}$ to zero, respectively, i.e. $\frac{\partial z}{\partial v_{E}}=0$ and $\frac{\partial z}{\partial v_{N}}=0$, and checking that the values of $v_{E}$ and $v_{N}$ are within the allowed interval. If not, one must also check the upper and lower limits of the speed interval.

As discussed and analyzed in Fagerholt et al. (2015), the introduction of ECAs may also affect what is the optimal sailing path between ports. By defining alternative sailing leg options between the ports (giving different values of $D_{E}$ and $D_{N}$ ), and solving this for each sailing leg option, we can compare the options, and determine which leg option is most profitable.

In the above we assume that the ship's route does not involve pickup and delivery scenarios that may radically change the ship's payload along it. This means that ship 
payload along the route can be reasonably assumed constant and hence the conceivable dependency of fuel consumption on ship payload can safely be ignored ${ }^{2}$. If ship payload is constant along a roundtrip, it can be shown that the above analysis is also valid for any roundtrip where the ship sails in and out of ECAs. In that case, the revenue $R$ denotes the total revenue for the roundtrip, while the distances $D_{E}$ and $D_{N}$ are the total distances along the roundtrip within and outside the ECA, respectively.

\subsection{Example and sensitivity analysis}

The model described in Section 2.1 has been tested on a realistic example case. In this case we have used fuel consumption data for a real ship transporting cars and trucks (so-called Pure Car and Truck Carrier, or PCTC). This ship has for all practical purposes minimum and maximum speeds of 15 and 21 knots, respectively. In our base case, we have used fuel prices of 294.50 USD/tonne for HFO and 589 USD/tonne for MGO (gathered from Bunkerworld.com (Bunkerworld, 2015) for Houston). This gives a ratio of 2.0 between the price of MGO and HFO. Furthermore, we have used the voyage between Antwerp and Halifax as an example in our analysis. This voyage has a total distance of 2873 nautical miles, including 773 miles within the ECA, i.e. $D_{E}=773$ and $D_{N}=2100$. This means that $26.9 \%$ of the sailing distance is within the ECA in our base case. Furthermore, we define a revenue ratio, for which a value of 1.0 gives the revenue per sailing leg of $R$, which has been estimated based on data from a shipping company. Different values of the revenue ratio correspond to different market situations. Due to confidentiality reasons, we do not show the actual value of the revenue, $R$.

In addition to the solve the problem with the numbers given above for our base case, we will in the following present analyses showing the sensitivity on the optimal speeds within and outside ECA for different

- ratios of MGO/HFO fuel prices for the above voyage,

- ratios of the distance within the ECA (which could be the case for other voyages), and

- revenue ratios, showing the effect on optimal speeds from various revenue rates, reflecting different market situations.

\section{Fuel sensitivity:}

In this analysis the price of HFO has been kept fixed, while we have changed the price of MGO giving different ratios of the price of MGO compared to HFO. This

\footnotetext{
${ }^{2}$ A fortiori, changes in ship payload due to fuel consumption are too small to cause noticeable changes in fuel consumption and can safely be ignored too. See Psaraftis and Kontovas (2013) for a discussion of factors that may affect fuel consumption.
} 
means that when the ratio between the MGO and HFO prices increases, so does the total fuel costs for sailing the voyage, and vice versa.

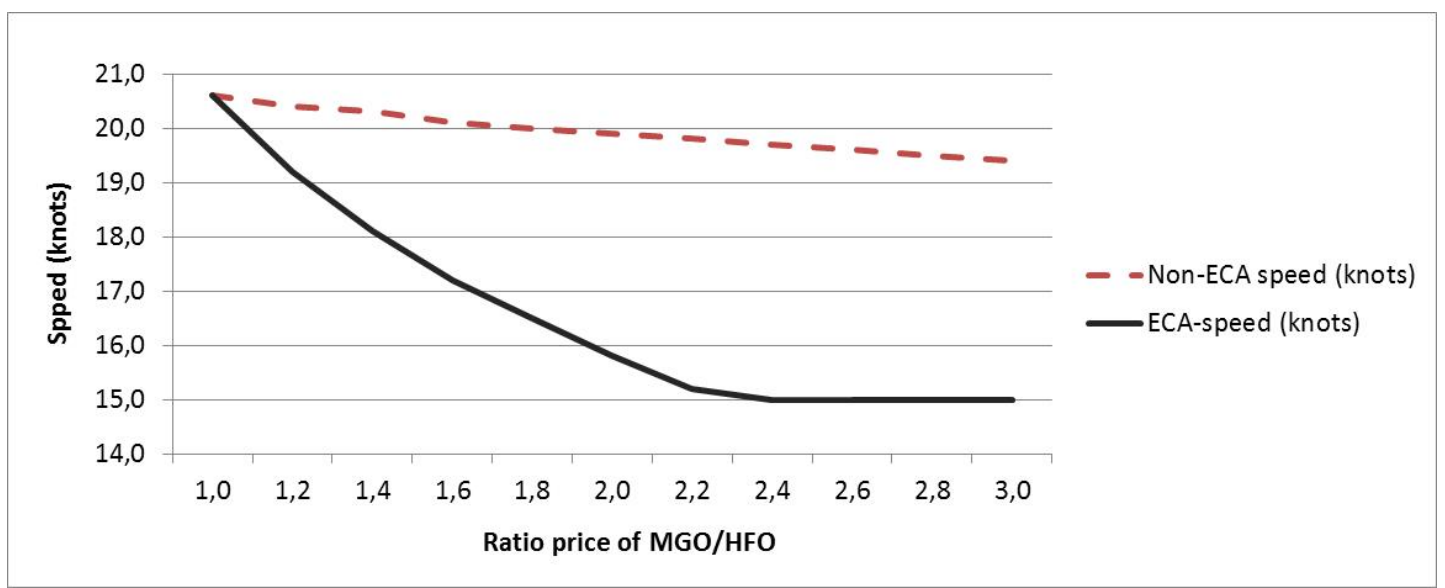

Figure 2: Optimal speeds within and outside the ECA as a function of the ratio of the fuel price of MGO/HFO

Figure 2 shows that for the base case with a ratio of 2.0 between the price of MGO and HFO, the optimal speeds within and outside the ECA are 15.8 and 19.9 knots, respectively. Due to the higher fuel price, it is rather intuitive that the optimal speed within the ECA is smaller than the speed outside. However, the magnitude of the speed difference shows the importance of taking the ECA into account when determining the optimal speeds.

As shown in Figure 2, when the fuel price ratio decreases, so does the difference of the two speeds, and vice versa. We may also note that when the ratio decreases, meaning that the total fuel costs become less important compared to the revenue of sailing the voyage, both speeds increase, and vice versa. Finally, we see from Figure 2 that the optimal speed within the ECA reaches the ship's minimum speed of 15 knots when the fuel price ratio is 2.4 or larger.

Sensitivity with respect to ratio sailed within the ECA:

In this analysis we show how the optimal speeds within and outside the ECA vary with varying distance within the ECA compared to the total sailing distance. As mentioned previously, in the base case used in the analysis shown in Figure 2, the distance within the ECA was $26.9 \%$ of the total distance. 


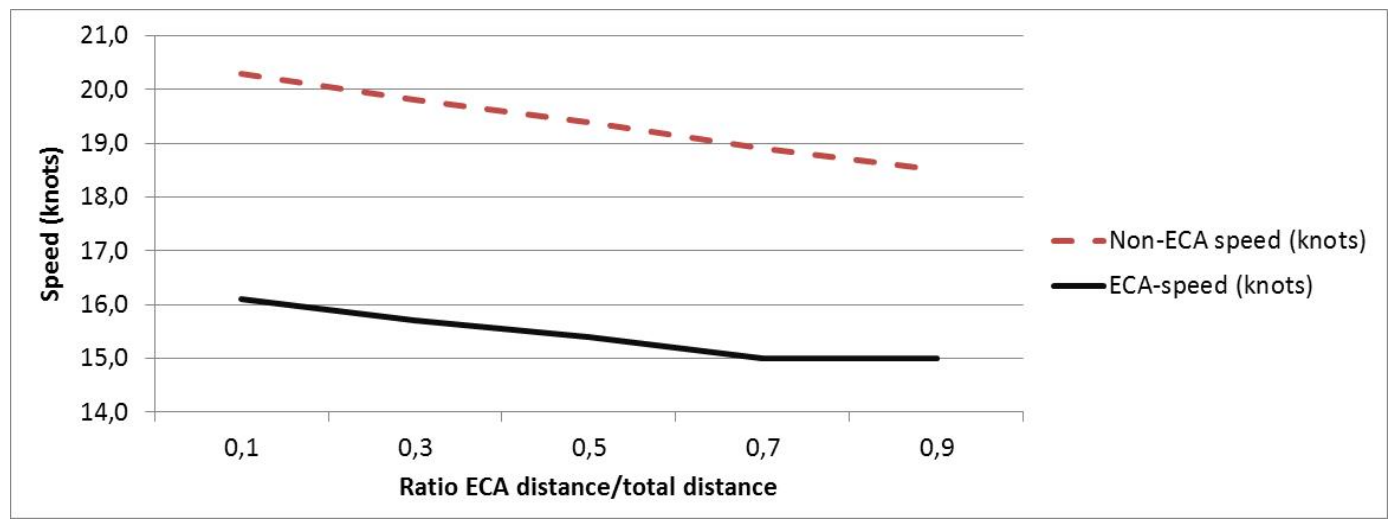

Figure 3: Optimal speeds within and outside the ECA as a function of the distance within the ECA compared to the total distance sailed

Figure 3 shows that both speeds decrease with increased distance within the ECA. This is natural since it means that the ship has to use more of the expensive fuel, and the fuel costs become more dominant.

\section{Sensitivity with respect to revenue per voyage:}

Here, we show how the optimal speeds vary with respect to the revenue per voyage, $R$. It should be noted that a revenue ration of 1.0 corresponds to what have been used in the analyses shown in Figures 2 and 3. A ratio less than 1.0 indicates a slow market with reduced rates, while a higher a higher ratio corresponds to a good market with high rates.

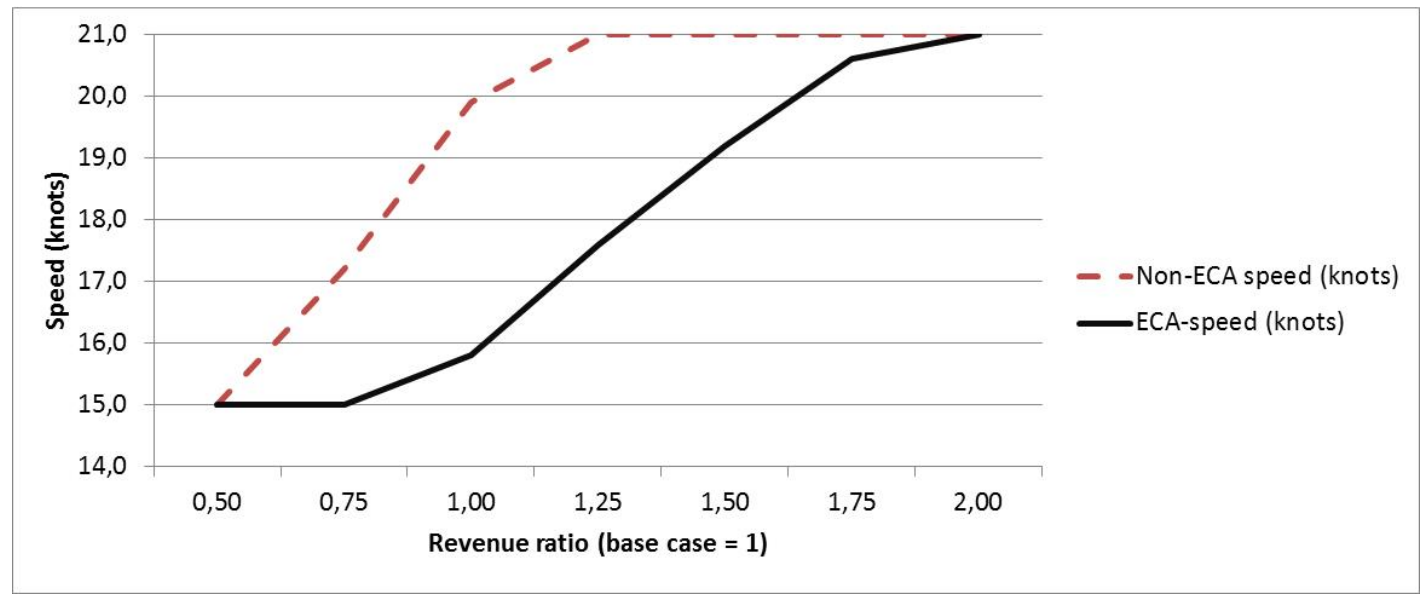

Figure 4: Optimal speeds within and outside the ECA as a function of the revenue

Figure 4 shows, as expected, that both speeds increase when the revenue increases. This can be explained by noting that when the revenue per voyage increases, one wants to increase the speed to be able to perform more voyages per unit time. It can also be noted that for a revenue ratio of 1.25 and higher, the optimal speed outside 
the ECA reaches the ship's maximum speed of 21 knots, while the optimal speed within the ECA is similar to the minimum speed for ratios of 0.75 and lower.

\section{THE ECA REFRACTION SPEED OPTIMIZATION PROBLEM}

In this section we consider another, though related, speed optimization problem that arises in the presence of ECAs. The relation of this problem to the problem of Section 2 will be discussed later. Assume a ship sailing from $A$ to $B$, where $A$ is within an ECA, while $B$ is outside, as illustrated in Figure 5.

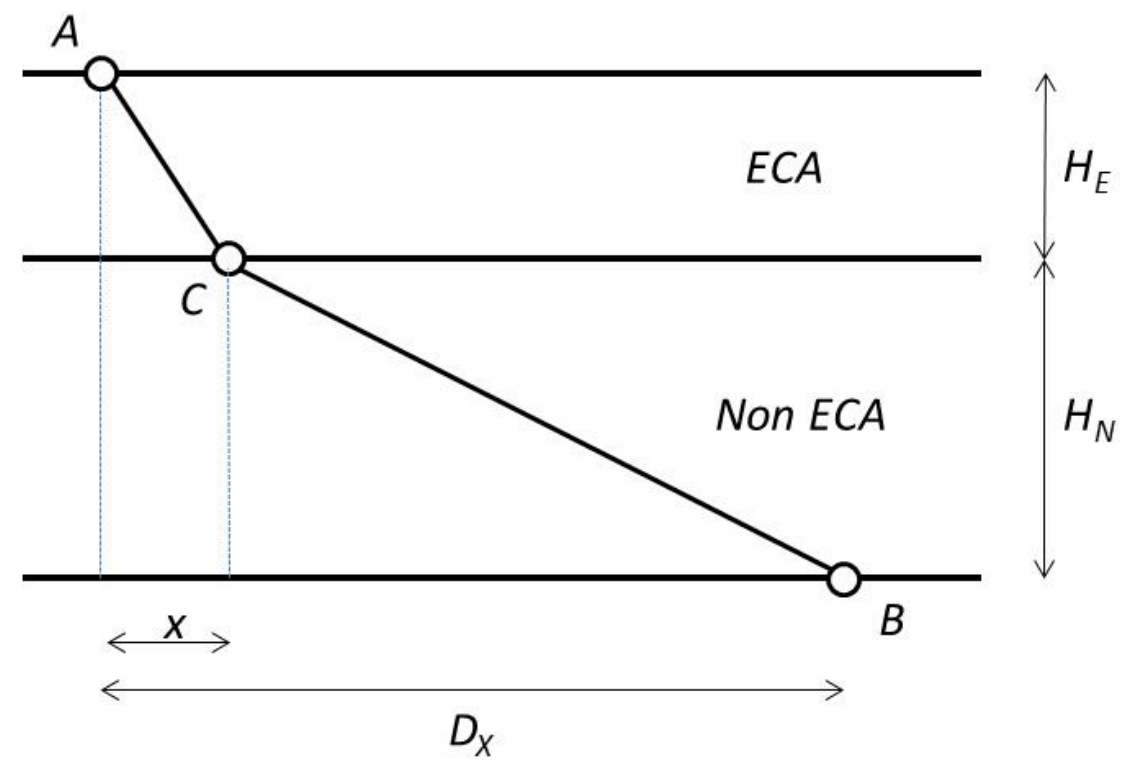

Figure 5: Illustration of the ECA refraction problem

We still assume that the ship must use expensive fuel (MGO) within the ECA, while it can switch to normal fuel (HFO) outside the ECA. The ECA refraction and speed optimization problem consists of determining the speeds within and outside the ECA, respectively, as well as the refraction point $C$, where the ship leaves the ECA and enters the non ECA, which maximizes daily profit. Point $C$ will be defined by $x$, as illustrated in Figure 5. Distances $H_{E}, H_{N}$ and $D_{x}$, also as defined in Figure 5, are assumed to be known. It is assumed that there are no obstacles such as islands, peninsulas or other physical barriers that would prevent the ship to travel directly from $A$ to $C$ and then directly from $C$ to $B$. If this is not the case, the analysis can still be performed but would be more involved as it should also include a determination of the path around the barrier.

It should be noted parenthetically that in the equivalent refraction problem in an optical scenario in which the speed of light is different within two adjacent media, the refraction point is such that the travel time of light from origin to destination is 
minimized. The optical refraction problem is an 'easier' version of the ECA refraction problem, in the sense that the speed in each of the media is fixed. It can also be proven in the optical refraction problem that light would follow a path that would minimize travel time.

It should also be noted that in the case where point $C$ in Figure 5 lies within another ECA, another refraction point $D$ would be needed. This problem would be a straightforward extension of the single refraction point problem illustrated in Figure 5 , and which is considered in the following mathematical analysis.

\subsection{Mathematical formulation}

We consider, as in Section 2, a situation where there is a given income for sailing the leg given by $R$, and a cubic relationship between ship speed and fuel consumption per time unit. Using the notation introduced in Figure 5, the distances for the sailing within and outside the ECA can be defined as $\sqrt{H_{E}^{2}+x^{2}}$ and $\sqrt{H_{N}^{2}+\left(D_{x}-x\right)^{2}}$, respectively. Sailing with the speed $v_{E}$ and $v_{N}$ within and outside the ECA, respectively, the total sailing time becomes

$$
\frac{\sqrt{H_{E}^{2}+x^{2}}}{v_{E}}+\frac{\sqrt{H_{N}^{2}+\left(D_{x}-x\right)^{2}}}{v_{N}}
$$

where the first term represents the sailing time within the ECA and the second outside the ECA.

We note here parenthetically is that in reality ships follow the great circle distance routes between two points, while we have approximated the distances using the Pythagorean theorem, which applies to Euclidean two-dimensional geometry and also conforms to the two-dimensional nature of maritime maps. If the approximation introduced by the Pythagorean theorem is not considered satisfactory, then one can always drop the square root term $\sqrt{H_{E}^{2}+x^{2}}$ in favor of a more accurate function $f\left(H_{E}, x\right)$ that gives the real great circle distance between points $\mathrm{A}$ and $\mathrm{C}$, and do the same with the distance between points $C$ and $B$. The analyses will otherwise remain the same.

Furthermore, it can easily be shown that the fuel consumption per distance unit becomes a quadratic function. Using the same notation as in Section 2, the fuel cost per distance unit within and outside the ECA can be defined as $F C_{E} v_{E}^{2}$ and $F C_{N} v_{N}^{2}$, respectively.

The total profit for the sailing leg can now be calculated as follows: 


$$
R-F C_{E} v_{E}^{2} \sqrt{H_{E}^{2}+x^{2}}-F C_{N} v_{N}^{2} \sqrt{H_{N}^{2}+\left(D_{x}-x\right)^{2}}
$$

The first term is the income for the sailing leg, while the next two terms calculate the fuel costs for the sailing within and outside the ECA, respectively.

The daily profit, which we want to maximize, can be defined by dividing the expression in (4) by the total sailing time defined in (3), which gives the following optimization problem:

$$
\max z=\frac{\left(R-F C_{E} v_{E}^{2} \sqrt{H_{E}^{2}+x^{2}}-F C_{N} v_{N}^{2} \sqrt{H_{N}^{2}+\left(D_{x}-x\right)^{2}}\right)}{\frac{\sqrt{H_{E}^{2}+x^{2}}}{v_{E}}+\frac{\sqrt{H_{N}^{2}+\left(D_{x}-x\right)^{2}}}{v_{N}}}
$$

subject to

$$
\underline{V} \leq v_{E}, v_{N} \leq \bar{V}
$$

We may also include non-negative requirements on the $x$ variable. However, this is strictly not necessary since the optimal solution will always give non-negative values of $x$ as long as the sailing costs within and outside the ECAs are positive.

While the speed optimization problem in Section 2 had two decision variables, i.e. the two speeds within and outside the ECA, this problem also has third decision variable $x$ for the refraction point. Again, this can be solved by setting the partial derivatives of $z$ with respect to $x, v_{E}$ and $v_{N}$, to 0 , respectively, which will give the optimal solution if the speeds are within their feasible interval. Otherwise, the optimal speeds can be found on their limits.

Again, if we assume that the ship's fuel consumption is not dependent on the load on board the ship or if the load onboard is the same on the return trip from $B$ to $A$, the above analyses will also be valid for the roundtrip case (i.e. from $A$ to $B$ and back to $A$ ).

What is the relation between Ronen's extension as described in Section 2 and the ECA refraction problem as described above? Even though in the former problem the shapes of the paths within and outside the ECA can be general, and all that matters are distances $D_{E}$ and $D_{N}$, in case these paths are straight lines it can be seen that the former problem is a constrained version of the latter. In this case, assuming $D_{E}$ and $D_{N}$ are known and constant is the same as assuming $x$ fixed. This means that the objective function of (1) can be derived from the one of (5) by the following 
substitutions: $D_{E}=\sqrt{H_{E}^{2}+x^{2}}$ and $D_{N}=\sqrt{H_{N}^{2}+\left(D_{x}-x\right)^{2}}$. This also means that the optimal value of the problem defined in (1) is a lower bound to the equivalent one of (5), if all other inputs are the same.

\subsection{Example and sensitivity analysis}

Suppose, as in the previous example, that the fuel that must be used in the ECA is twice as expensive as the fuel that can be used outside. Furthermore, assume $D_{x}=400, H_{N}=H_{E}=200$. This is also in accordance with that the ECA goes 200 nautical miles outside the coastline. Since it is natural to assume that a longer voyage has a higher revenue, we adjust the value used in Section 2.2 for the revenue per sailing leg, $R$, so that it has the same value per distance unit. Then, we get the following relations between total sailing cost, total distance sailed (second axis in the figure below) and the value of $x$ (first axis).

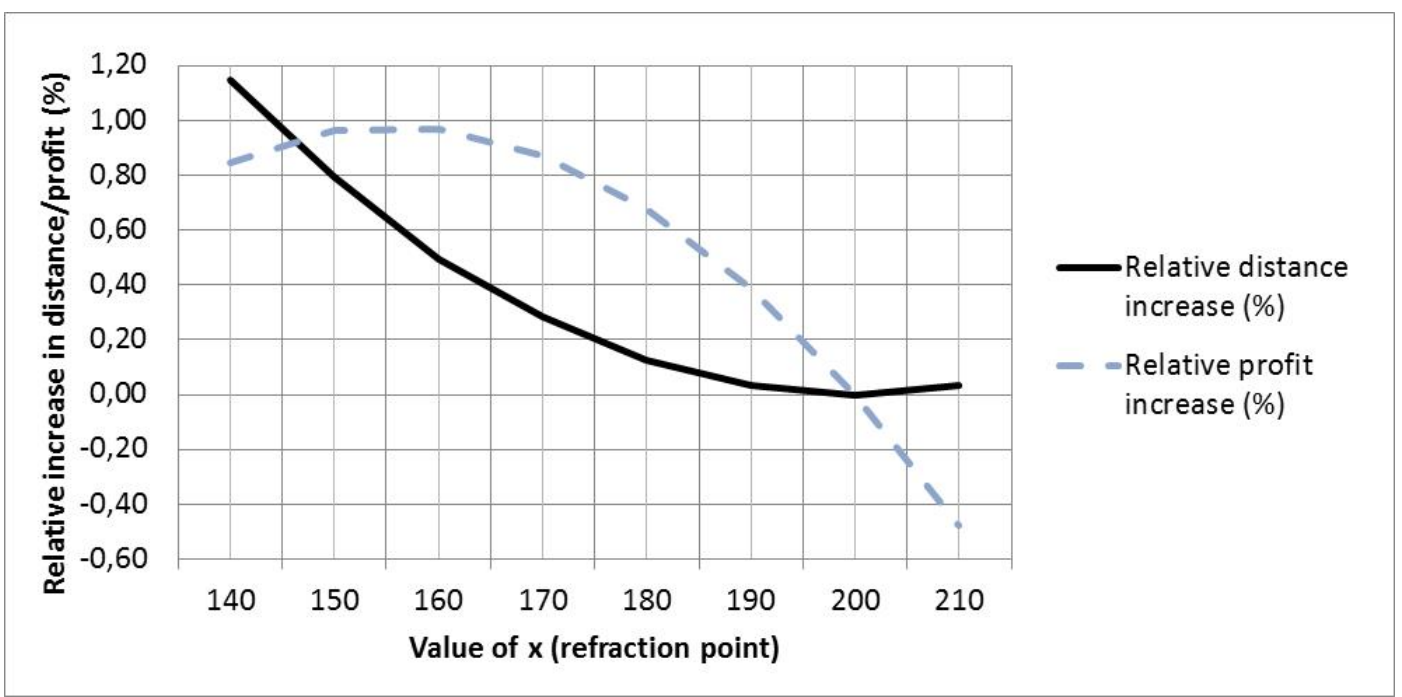

Figure 6: Relationship between profit and total distance as a function of the value of $x$ (refraction point). All values are normalized against the values for $x=200$, which corresponds to the shortest voyage (with a distance of 565.7).

Looking at Figure 6, we can see that the value of $x$ that gives the highest daily profit is approximately 155. This gives an increase of the daily profit of about $1 \%$ compared to sailing the shortest distance (at $x=200$ ). It is interesting to note that the optimal speeds, which are not shown in Figure 6, varied with less than 0.1 knots for the different values of $x$ that were tested. Their values were approximately $v_{E}^{*}=15.4$ and $v_{N}^{*}=19.4$. This shows that the optimal speeds are robust with respect to the chosen refraction point. It also indicates that a simplified solution approach, where the optimal speeds are first determined for a given value of $x$, and then subsequently determine the optimal value of $x$ for the given speeds, will provide close to optimal solutions. 
In the analysis above we have used the values $D_{x}=400, H_{N}=H_{E}=200$, see Figure 5, and assumed that MGO is twice as expensive as HFO (i.e. fuel price ratio $\mathrm{MGO} / \mathrm{HFO}=2$ ). It can also be interesting to analyze how the optimal refraction point varies with $D_{x}$ for different fuel price ratios. However, increasing $D_{x}$ while keeping all other parameters fixed will also increase the sailing distance of the voyage between points $A$ and $B$ (Figure 5). We let the revenue per sailing leg, $R$, vary linearly with the (shortest) distance for the voyage in order to reflect that longer voyages normally have higher revenues.

Figure 7 shows the optimal refraction point as a function of $D_{x}$ for three different fuel price ratios (assuming the values of $H_{N}$ and $H_{E}$ are kept fixed).

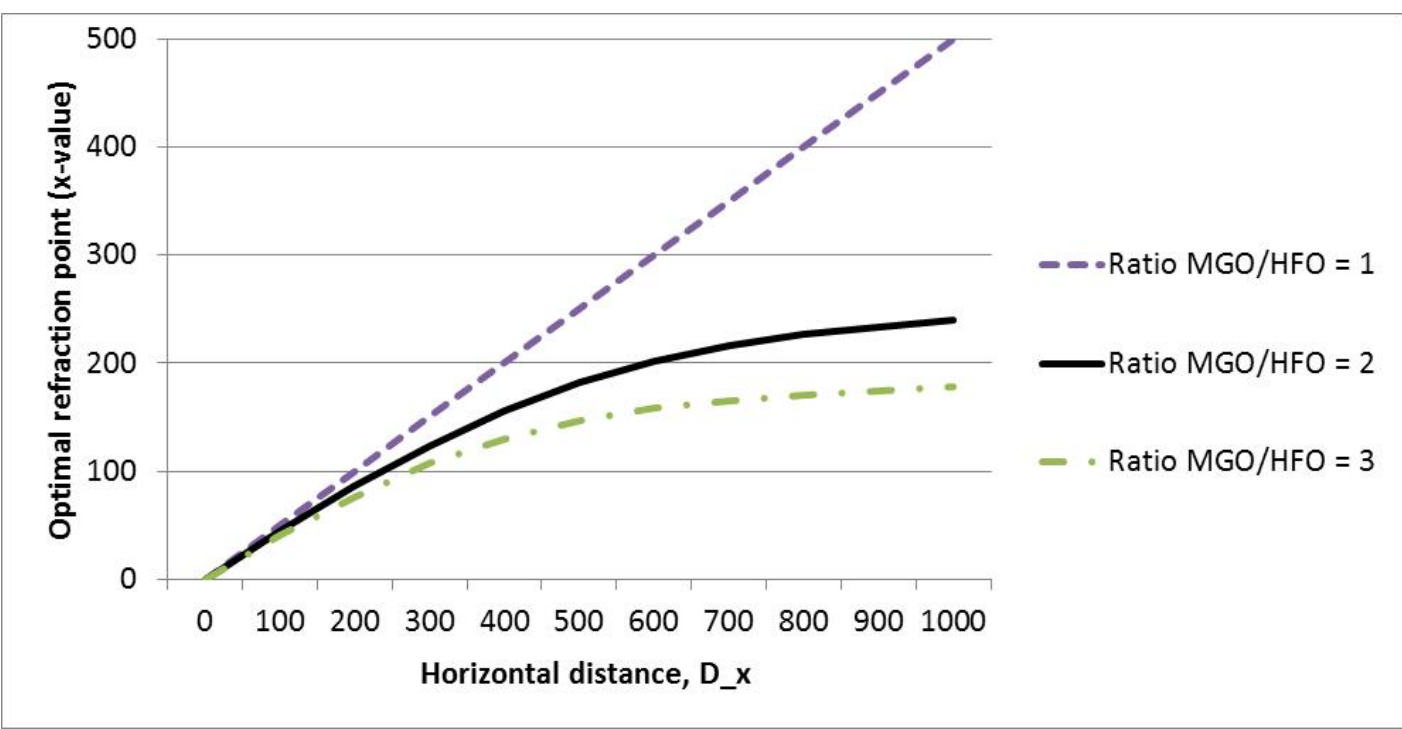

Figure 7: Optimal refraction point as a function of horizontal distance, $D_{x}$, for various ratios of fuel price of MGO to HFO

When the fuel price ratio is 1 , i.e. the price of the two fuels are the same, it is always optimal to sail the shortest route, which is a straight line from A to $B$. In fact it can be shown that in this case $x=\frac{D_{x} H_{E}}{H_{E}+H_{N}}$. With the numbers used in this example this gives an optimal value of $x$ that is equal to $\frac{D_{x}}{2}$, which is also shown in Figure 7. However, when the fuel price ratio increases, i.e. MGO becomes more expensive than HFO, the optimal refraction point increases at a much slower pace, especially for high values of $D_{x}$. Actually it can be shown that when $D_{x}$ goes to infinity (or becomes very large), the optimal value of $x$ asymptotically reaches a maximum bounded value provided that the fuel price ratio is greater than 1 . In our examples these $x$-values are 260.9 and 191.5 for the fuel price ratios of 2 and 3, respectively. 
The above shows again that for high fuel price ratios, it is optimal for the ships to sail short distances within the ECA and longer distances outside. Although in a somewhat different problem context, this also corresponds to the findings in Fagerholt et al. (2015).

\section{DISCUSSION AND CONCLUDING REMARKS}

Fuel costs have become an important cost item in shipping, sometimes accounting for more than $50 \%$ of the total operational costs. Strict limits on the maximum sulphur content in fuel used by ships have recently been imposed by MARPOL in some Emission Control Areas (ECAs). In order to comply with these regulations many ship operators will need to switch to low-sulphur fuel (e.g. Marine Gas Oil (MGO)) when sailing inside ECAs. Low-sulphur fuel is more expensive than normal Heavy Fuel Oil (HFO), which can be used outside the ECAs, and the new ECA regulations will therefore impact international shipping in several ways.

In this paper we considered two new speed optimization problems that arise for ships that use fuel switch and sail in and out of ECAs, such as for instance deep-sea vessels. The first problem was similar as the one introduced by Ronen (1982), though extended to the situation with ECAs. The second problem was the so-called ECArefraction problem, which, in addition to optimal speeds, calls for the determination of the optimal crossover point through the ECA boundary. In both cases the objective of the problem was to maximize daily profit. We proposed a mathematical formulation for each of the two problems and provided some test examples including sensitivity analyses.

In terms of managerial implications, we believe that the value of this paper is to help carriers refine their routing when moving in and out of ECAs. The paper has shown that some benefits can be obtained if such an optimization is performed. The method can be applied not only to car carriers, which was the example used here, but to other types of ships as well.

\section{ACKNOWLEDGEMENTS}

The work of $K$. Fagerholt was carried out with financial support from the GREENSHIPRISK project, partly funded by the Research Council of Norway. The work of $\mathrm{H}$. N. Psaraftis was supported by an internal grant at the Technical University of Denmark. 


\section{REFERENCES}

Balland, O., Erikstad, S. and Fagerholt, K., 2012. Optimized selection of air emission controls for vessels. Maritime Policy \& Management 39(4), 387-400.

Balland, O., Erikstad, S., Fagerholt, K. and Wallace, S., 2013. Planning vessel air emission regulations compliance under uncertainty. Journal of Marine Science and Technology 18(3), 349-357.

Brynolf, S., Magnusson, M., Fridell, E. and Andersson, K., 2014. Compliance possibilities for the future ECA regulations through the use of abatement technologies or change of fuels. Transportation Research Part D: Transport and Environment 28, 6-18.

Bunkerworld, 2015. www.bunkerworld.com/prices/. Website accessed March 20, 2015.

Cullinane, K. and Bergqvist, R., 2014. Emission control areas and their impact on maritime transport. Transportation Research Part D: Transport and Environment 28, $1-5$.

Fagerholt, L., Gausel, N. T., Rakke, J. G. and Psaraftis, H. N., 2015. Maritime routing and speed optimization with emission control areas. Transportation Research Part C: Emerging Technologies 52, 57-73.

IMO, 2014. International Maritime Organization websites. Available from: <http://www.imo.org/OurWork/Environment/PollutionPrevention/AirPollution/Page s/Air-Pollution.aspx>. [accessed 30.03.2014]

Jiang, L., Kronbak, J. and Christensen, L., 2014. The costs and benefits of sulphur reduction measures: Sulphur scrubbers versus marine gas oil. Transportation Research Part D: Transport and Environment 28, 19-27.

Panagakos, G., Stamatopoulou, I.V. and Psaraftis, H.N., 2014. The Possible Designation of the Mediterranean as a SECA: a Case Study. Transportation Research Part D: Transport and Environment 28, 74-90.

Psaraftis, H. and Kontovas, C., 2013. Speed models for energy-efficient maritime transportation: A taxonomy and survey. Transportation Research Part C: Emerging Technologies 26, 331-351.

Ronen, D., 1982. The effect of oil price on the optimal speed of ships. Journal of the Operational Research Society 33, 1035-1040.

Smith, T. W. P., Jalkanen, J. P., Anderson, B. A., Corbett, J. J., Faber, J., Hanayama, S., O'Keeffe, E., Parker, S., Johansson, L., Aldous, L.,Raucci, C., Traut, M., Ettinger, S., Nelissen, D., Lee, D. S., Ng, S., Agrawal, A., Winebrake, J.J., Hoen, M., Chesworth, S., 
Pandey, A. (2014), Third IMO GHG Study 2014, International Maritime Organization (IMO) London, UK, June. 